\title{
Age of First Infection of Pulmonary Tuberculosis in Dhaka Metropolitan City Jahida Gulshan ${ }^{1} *$ and Subrina Farah ${ }^{2}$ \\ ${ }^{1}$ Institute of Statistical Research and Training, Dhaka University, Dhaka-1000, Bangladesh \\ ${ }^{2}$ Social and behavioural science unit, ICDDR,B Dhaka, Bangladesh
}

(Received: 5 March 2013; Accepted: 29 August 2013)

\begin{abstract}
This study aims to determine the age of first infection of pulmonary tuberculosis in Dhaka, the capital of Bangladesh. Registered cases at an arbitrarily selected chest disease clinic in Dhaka under the National Tuberculosis Control Program (NTP) of Bangladesh was considered for this study. From the study of the sample of 303 cases, it was revealed that women are more likely to be affected by Tuberculosis bacilli at earlier ages as compared to men in Dhaka. Mann Whitney Median test showed a significant difference between the median age of first infection of male and female (p-value $<0.001$ ). In addition it is also observed that there is a significant difference (p-value $<0.05$ ) between the median age of first infection between people with in-house occupational activities and individuals with outgoing occupational activities where outgoing people are infected by Tuberculosis bacilli at later ages than in-house workers. An exponential regression model shows significant effect of the variables sex and place of occupational activities on the age of first infection (p-value $<0.05)$.
\end{abstract}

Key Words: Empirical survival function, Hazard function, Median test, Exponential regression model

\section{Introduction}

Nearly one-third of the global population is infected with Mycobacterium tuberculosis and thus at a risk of developing the disease ${ }^{1}$. It is the first infectious disease declared by the World Health Organization (WHO) as a global threat for health ${ }^{2}$. More than $90 \%$ of global TB cases and deaths occur in the developing world, where $75 \%$ of these cases are in the economically most productive age group of 15 to 54 years ${ }^{3}$. The discovery of chemotherapy in the 1940s and adoption of the standardized short course in the 1980s resulted in a declining trend in prevalence of TB in some developed countries ${ }^{4}$. However, the picture of the developing countries is not the same. In developing countries, about $7 \%$ of all deaths are attributed to TB which is the most common cause of death from a single source of infection among adults ${ }^{5}$. According to a global estimate in 2007, there were 9.27 million incidents of TB, 13.7 million prevalent cases, 1.32 million deaths from TB in HIV-negative and 0.45 million deaths in HIV-positive persons ${ }^{6}$. Asia and Africa alone constitute $86 \%$ of all cases ${ }^{6}$.

Tuberculosis is a major public health problem in Bangladesh. Bangladesh ranked the 6th highest for the burden of TB among 22 high-burden countries in 2007, with 353,000 new cases, 70,000 deaths, and an incidence of 223/100,000 people per year ${ }^{6}$. The problem is aggravated by the increasing population density, rapid urbanization, poverty and illiteracy ${ }^{3}$. According to several studies conducted with the view to compare infection and disease rates, women of reproductive age have shown high progression rate to disease from infection compared with men of same age group ${ }^{7}$. Yet case notification rates for TB in SAARC region show higher rates for males with approximately 2:1 male to female ratio ${ }^{8}$. A national morbidity survey in Bangladesh (1994-95) showed 2.1:1 male to female prevalence ratio for TB. There was an apparent gender dissimilarity in TB with men being more frequently detected than women with a female male ratio ranging from 0.24 to $0.39^{9}$.
There are several challenges faced by developing countries which need to be addressed for effective control of TB, that includes, among others, (particularly in developing countries) the development of an effective surveillance system, accelerated identification of cases and others ${ }^{10}$. Few studies were done on Tuberculosis patients of Bangladesh and especially in the city of Dhaka city. Being the capital of Bangladesh, it is important to know that pattern in age at first infection as well as any relationship between age and sex or age and place of occupational activities of the TB patients. However, the main objectives of the study are to

a) observe the pattern of age of first infection of pulmonary tuberculosis in Dhaka Metropolitan City

b) check whether there is any relation between age of first infection and sex as well as age of first infection and place of occupational activities of the patients.

c) compute and compare probabilities of first infection with respect to place of occupational activities and sex of the patients where age of first infection is obtained in terms of age at which one becomes a TB case for the first time.

d) fit an appropriate model for the age of first infection of the TB patients of Dhaka city.

\section{Data and Variables}

Data have been collected from Chest Disease Clinic (CDC) located at Shyamoli, Dhaka. Chest Disease Clinics are one of the organizations of urban areas of Bangladesh along with other health organizations from where TB data are collected under the National Tuberculosis Program (NTP) in collaboration with World Health Organization (WHO) and Government of Bangladesh. Information of every suspected TB patient who has encountered as well as taken treatment from the CDC are recorded in a registrar book. From the registrar books of Shyamoli CDC, all pulmonary tuberculosis patients enrolled between the years January 2007 and August 2009 are taken into consideration. Among the variables recorded in the registrar book of National Tuberculosis Program (NTP) for every registered individual's status,

*Author for Correspondence.e-mail: gulshan@isrt.ac.bd 
following variables are considered in the study: Age, Sex and Occupation. Since this study uses data from data recorded in the register book as mentioned earlier, some other variables, e.g. socio-economic status or education level could not be considered in the study although these are thought to have significant impact in the age of first infection. Age is recorded as a continuous variable presenting the age of first infection which is the survival time or lifetime here. Sex of patients is a dichotomous variable and recorded as male or female in the registrar book. In the sample we found TB patients from diverse occupations including garments worker, housewife, maid servant, business man, service holder, student, teacher, child, rickshaw driver, driver, day labour, week labour, barber, electrician, farmer, nurse, security guard, unemployed, retired officer and disable. We stratified the various types of occupations into two groups for further analysis based on their place of activities and frequency of interaction with other people. For this purpose, all male patients (except male child, unemployed, retired and disabled) and female patients with certain occupations (i.e. business, service, teacher, student, garments worker, day labourer, week labourer, nurse) are considered into a group named 'Outgoing'. On the other hand, children (not student), house wives, maid servants, unemployed, retired officer and disabled people are classified as 'In-house worker'.

\section{Methodology}

Frequency distribution tables were constructed to examine the pattern of age of first infection and the factors sex and place of occupational activities. Summary measures are estimated for age of first infection at different levels of the factors. Empirical survival functions are obtained for comparing the probabilities of first infection of male and female as well as that of different work place at different ages. The Mann-Whitney test is used to compare the median age of first infection from two populations. This test works when the dependent variable is continuous, discrete-ordinal or discrete-count, and the independent variable is discrete with two attributes. Finally Chi-square test of association has been used to check for possible association among the considered variables age, sex and occupation of the cases and exponential regression model is used to model the age at first infection and examine the effect of covariates on the age of first infection.

\section{Results and Discussion}

Table 1 shows the classification of TB patients by different independent variables.

Table 1. Classification of TB patients by Age, Sex and Place of Occupational Activities

\begin{tabular}{lll}
\hline Variable & & Frequency (\%) \\
\hline & 14 or less & $48(15.8)$ \\
& $15-24$ & $106(35)$ \\
Age & $25-34$ & $70(23.1)$ \\
& $35-44$ & $44(14.5)$ \\
& $45-54$ & $22(7.3)$ \\
& $55-64$ & $8(2.6)$ \\
Sex & 65 and higher & $5(1.7)$ \\
& Male & $193(63.7)$ \\
Place of & Female & $110(36.3)$ \\
Occupational & On house & $93(30.7)$ \\
Activities & Outgoing & $210(69.3)$
\end{tabular}

Almost two third of the total cases are male (table 1). This proportion is slightly different from National level where $68 \%$ of the reported TB patients are male and $32 \%$ are female ${ }^{2}$.

NTP, run by WHO and Government of Bangladesh reported the variable age classified in seven different groups, which has been adopted here to show the frequency of patients in different age groups. Age distributions are positively skewed, similar to the urban population's age pattern of National level data ${ }^{2}$. Place of Occupational Activities' for most of the patients (69.3\%). Only about $30 \%$ of the registered cases are found to work in house.

Table 2. Summary Measures of Age of First Infection with Respect to Sex

\begin{tabular}{|c|c|c|c|c|c|c|c|c|c|c|}
\hline \multirow{4}{*}{ Sex } & \multicolumn{4}{|c|}{ Mean } & \multicolumn{4}{|c|}{ Median } & \multicolumn{2}{|c|}{ Skewness } \\
\hline & \multirow[t]{3}{*}{ Estimate } & \multirow{3}{*}{$\begin{array}{l}\text { Std. } \\
\text { Error }\end{array}$} & \multicolumn{2}{|c|}{$95 \% \mathrm{CI}$} & \multirow[t]{3}{*}{ Estimate } & \multirow{3}{*}{$\begin{array}{l}\text { Std. } \\
\text { Error }\end{array}$} & \multicolumn{2}{|c|}{$95 \%$ CI } & \multirow[t]{3}{*}{ Estimate } & \multirow{3}{*}{$\begin{array}{l}\text { Standard } \\
\text { error }\end{array}$} \\
\hline & & & Lower & Upper & & & Lower & Upper & & \\
\hline & & & Bound & Bound & & & Bound & Bound & & \\
\hline $\mathrm{F}$ & 22.182 & 1.160 & 19.908 & 24.456 & 20.000 & .522 & 18.976 & 21.024 & 0.601 & 0.222 \\
\hline M & 28.946 & 1.056 & 26.875 & 31.016 & 27.000 & .922 & 25.194 & 28.806 & 0.782 & 0.167 \\
\hline Overall & 26.490 & .814 & 24.894 & 28.086 & 24.000 & .906 & 22.223 & 25.777 & 0.796 & 0.134 \\
\hline
\end{tabular}

Summary Measures for Age of First Infection with respect to Sex and Work Place:

Since the age distribution was positively skewed for comparing age of first infection, median is considered instead of mean. From Table 2 it is observed that, median age of first infection of female is noticeably lower than that of male, and the overall median age of first infection is 24 years. Median age of first infection implies that $50 \%$ of the infected women are infected at the age of 20 years whereas males are free from infection till late twenties (27 years). Considering all men and women, the $50 \%$ of the patients were first infected by the age of 24 years.

Mann-Whitney test has been performed to test the equality of median age of first infection for different sex. The test 
showed a significant difference between the distribution of age of first infection of male and female (P-value < 0.001).

Survival Probability and Hazard Function with respect to Sex:

There was no censored observation and no missing value in the data for variable 'Age'. Probabilities of first infection at different age are constructed using empirical survival function.

Figure 1 describes the age of first infection and figure 2 shows the hazard functions of male and female in the study population.

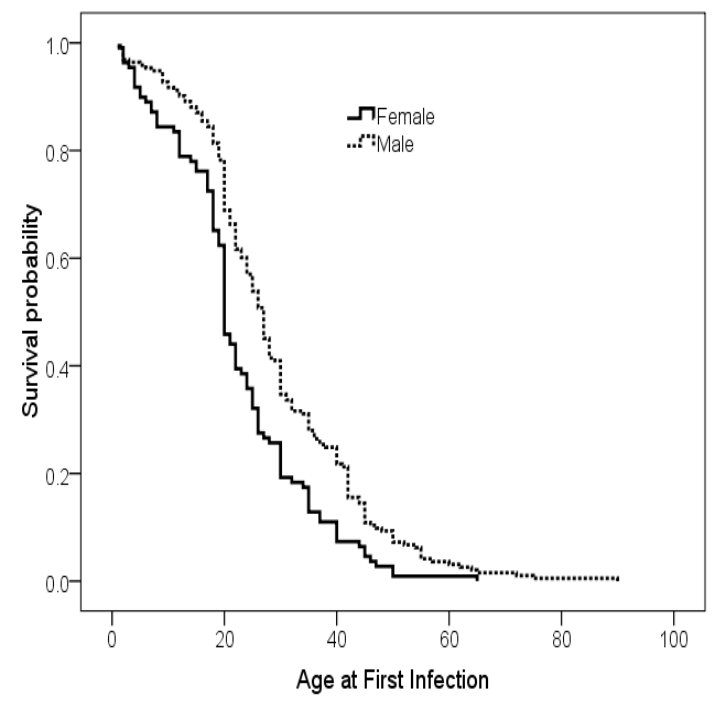

Fig.1. Survival Probabilities of Male and Female
Figure 1 shows that age of first infection of male is higher than that of female throughout their life span. In other words, men were infected by tuberculosis at later ages than women.

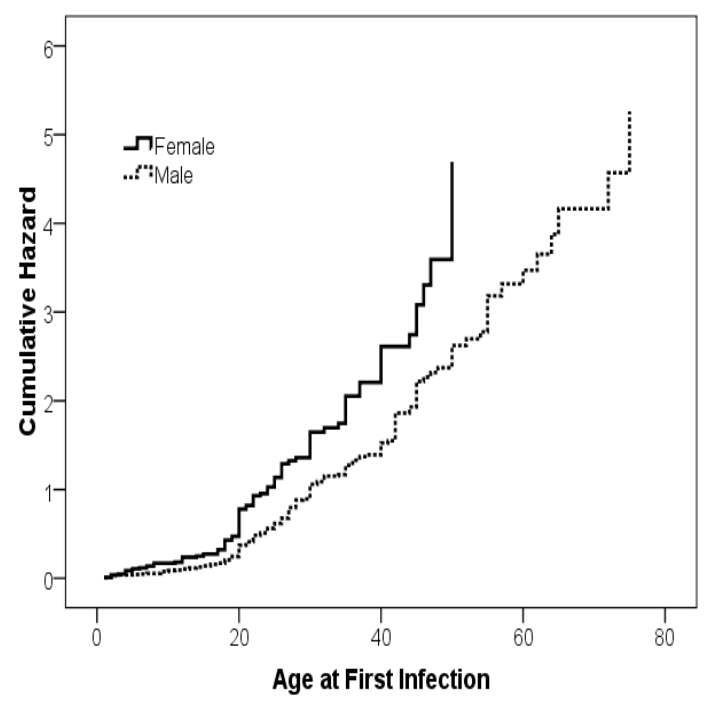

Fig. 2. Hazard Function with respect to Sex

Hazard function (Figure 2) also illustrates the same patterns as survival function; age specific failure rate of female is greater than male whereas at the early ages the failure rate for both male and female are very close.

Table 3. Summary Measures of Age of First Infection with Respect to Place of Occupational Activities

\begin{tabular}{|c|c|c|c|c|c|c|c|c|c|c|}
\hline \multirow[b]{3}{*}{$\begin{array}{l}\text { Place of } \\
\text { Activities }\end{array}$} & \multicolumn{4}{|c|}{ Mean } & \multicolumn{4}{|c|}{ Median } & \multicolumn{2}{|c|}{ Skewness } \\
\hline & \multirow[b]{2}{*}{ Estimate } & \multicolumn{3}{|c|}{$95 \%$ CI } & \multirow[b]{2}{*}{ Estimate } & \multirow[b]{2}{*}{$\begin{array}{l}\text { Std. } \\
\text { Error }\end{array}$} & \multicolumn{2}{|c|}{$95 \%$ CI } & \multirow[t]{2}{*}{ Estimate } & \multirow[t]{2}{*}{ Std. Error } \\
\hline & & $\begin{array}{l}\text { Std. } \\
\text { Error }\end{array}$ & $\begin{array}{l}\text { Lower } \\
\text { Bound }\end{array}$ & $\begin{array}{l}\text { Upper } \\
\text { Bound }\end{array}$ & & & $\begin{array}{l}\text { Lower } \\
\text { Bound }\end{array}$ & $\begin{array}{l}\text { Upper } \\
\text { Bound }\end{array}$ & & \\
\hline Outgoing & 29.324 & .885 & 27.590 & 31.058 & 26.000 & .836 & 24.361 & 27.639 & 0.881 & 0.155 \\
\hline In house & 20.091 & 1.561 & 17.032 & 23.151 & 20.000 & .680 & 18.668 & 21.332 & 0.687 & 0.260 \\
\hline Overall & 26.490 & .814 & 24.894 & 28.086 & 24.000 & .906 & 22.223 & 25.777 & 0.796 & 0.134 \\
\hline
\end{tabular}

Summary measures for Age of first Infection with respect to Place of Occupational Activities:

The estimated median age of first infection for indivduals working in-house are noticeably lower (20 yrs) than that of Outgoing individuals (26 yrs) (Table 3). In other words, younger people who work in-house is more prone to be infected by Tuberculosis bacilli than those who are not working in-house. Mann-Whitney test of Median showed a significant difference between the median age of first infection of individuals having different place of occupational activities (p-value $<0.001$ ).
Survival probabilities and Hazard rates with respect to Place of occupational Activities:

Empirical survival function was used to estimate the survival probabilities in terms of age of first infection and examined for the two types of places of occupational activities. 


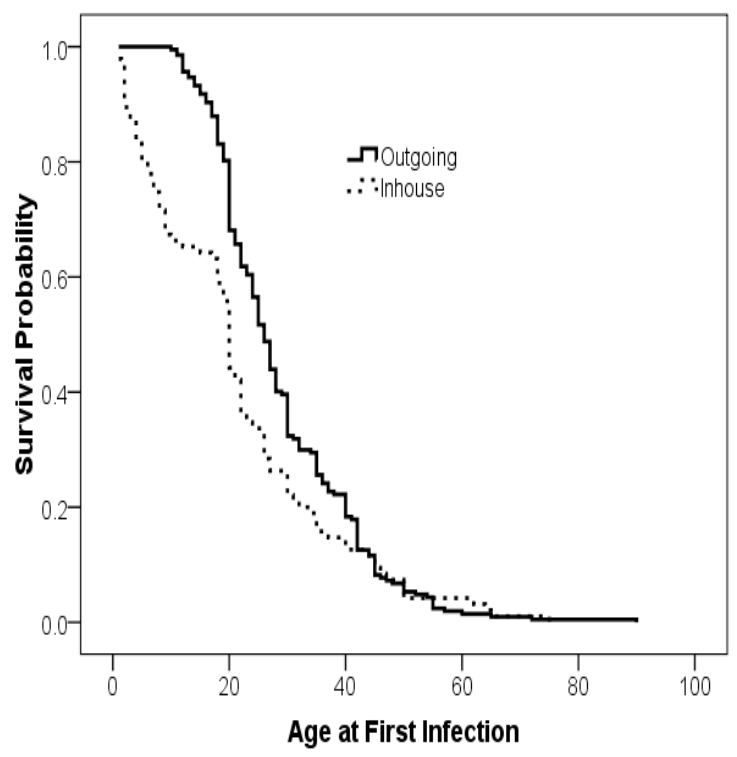

Fig. 3. Survival Function with respect to Work Place

Figure 3 indicates that, age of first infection of outgoing people is higher than the population working in-house. That is outgoing people gets infected later than people who work in-house. However, above the age 55, survival probabilities of both the in house workers and outgoing population are almost the same. Figure 4 shows that hazard rate (rate of getting infected) at specific age of population working inhouse is higher than the outgoing people.

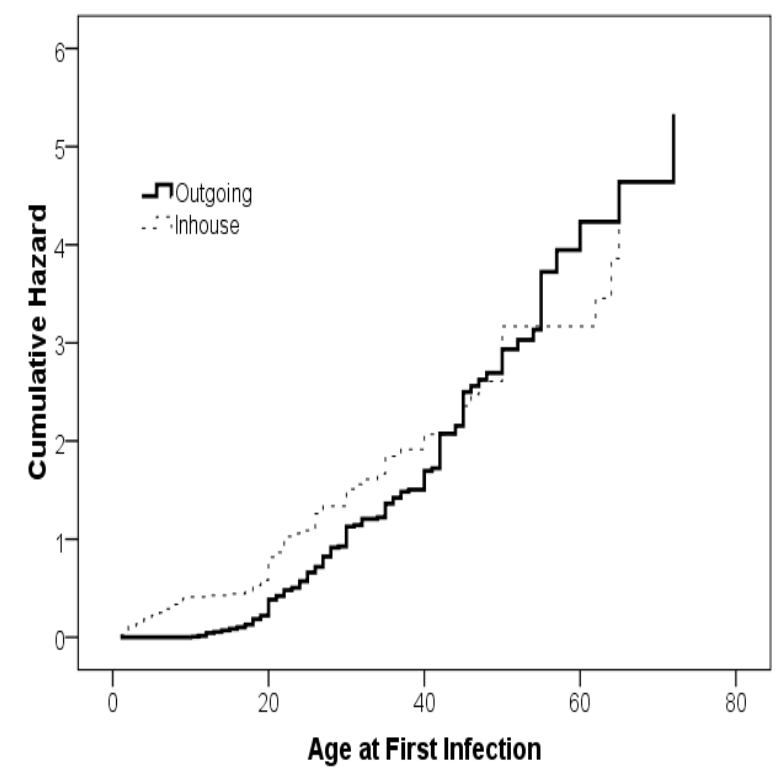

Fig. 4. Hazard Function with respect to Work Place

Exponential Regression Model for survival time (Age at first Infection):

Aim of using Exponential Regression Model was to determine the effects of independent variable sex and place of occupational activities on age of first infection of TB. The Model considered is

Age $=\exp (\mathrm{a}+\mathrm{b} *$ Place of Occupational Activities $+\mathrm{c} *$ Sex).
Here dummy variables were constructed and used in the Model for place of occupational activities(Outgoing =1) and sex (female=1).

Using $\mathrm{R}$ 2.14.0, the model is estimated as: Age $=\exp (3.17142+0.235 *$ Place of Occupational Activities - $0.186 *$ Sex). Both the variables, place of occupational activities and sex, are found to have significant effect (p-value $<0.01$ ) on age at first infection.

The estimated model clearly indicates that for both male and female, age at first infection is lower for those who work inhouse or for same place of occupational activities, age at first infection is lower for females. So people working in-house and the females are at the risk of getting infected at earlier ages.

\section{Conclusions}

One of the major goals of this study was to compare the age of first infection with respect to sex and work place of TB patients of Dhaka Metropolitan city. It is revealed that survival times were positively skewed for both men and women. Women are more likely to be affected by tuberculosis in earlier ages than men. The median survival time is higher for male than the female. The findings are similar to the National level data with slight difference in the median survival time of both the groups. Considering survival function and hazard function with respect to place of occupational activities, 'in-house' and 'outgoing', the outgoing people were found to survive longer than people working in-house and rate of getting infected for people working in-house is higher than the outgoing people. This could be an indication that the working environment, for people who works in-house, needs attention to be paid since studies found that confined, poorly ventilated working environment and overcrowding can increase the risk of getting infected by $\mathrm{TB}^{11}$.

Although the women are infected at earlier ages than men, only a little more than one third of the reported TB patients are women. Profound gender differentials existing in the SAARC member countries create numerous barriers for women, in seeking health care as well as in obtaining health care with special reference to diseases such as tuberculosis ${ }^{8}$. This could be assumed that women's poor health seeking behavior perhaps be a possible reason for lower case detection in TB for female.

It is important to note that $50 \%$ of the TB patients of Dhaka city are infected at early or late twenties. This might have major impact on our economy because infected by TB at this age restrict economic activities of the people. Moreover, for women, infected at this age have serious impact on the next generation of the country. In spite of the National Tuberculosis Program (NTP) in collaboration with World Health Organization (WHO) and Government of Bangladesh to control TB in the country, TB remained as a major problem in many parts of the country. The authors believe that identification of people at risk in turn would help policy makers to detect the most vulnerable groups and determine appropriate policies for them in order to make Bangladesh free of TB burden in near future. 


\section{References}

1. http://www.who.int/mediacentre/factsheets/fs104/en/ [accessed on July 24, 2013].

2. Kochi, A., 1991. The Global Tuberculosis Situation and the New Control Strategy of the World Health Organization. Tuberculosis, 71, 1-6.

3. Ministry of Health and Family Welfare, Bangladesh, 2008.

4. Chadha, V. K., 2009. Progress towards Millennium Development Goals for TB Control in seven Asian Countries. Indian Journal of Tuberculosis, 56:30-43.

5. Kaye, K. and T.R. Frieden, 1996. Tuberculosis Control: the Relevance of Classic Principles in an Era of Acquired Immunodeficiency Syndrome and Multidrug Resistance. Epidemiological Review, 18:52-63.

6. World Health Organization Global Tuberculosis Control 2009: Epidemiology, Strategy, Financing: WHO Report 2009. Geneva: World Health Organization.
7. Holmes, C.B., H. Hausler, and P. Nunn, 1998. A Review of Sex Differences in the Epidemiology of Tuberculosis. International Journal of Tuberculosis and Lung Diseases, 2(2), 96-104.

8. SAARC CANADA Regional tuberculosis and HIV/AIDS Project. Gender Differences among Tuberculosis Patients in National TB Control Programmes within SAARC Countries. 2001. 2-13.

9. Zaman, K, M. Yunus, S.E. Arifeen, A.H. Baqui, D.A. Sack, S. Hossain, Z. Rahim, M. Ali, S. Banu, M.A. Islam, N. Begum, V. Begum, R.F. Breiman and R.E. Black, 2006. Prevalence of sputum smear-positive tuberculosis in a rural area in Bangladesh. Epidemiology and Infection, 134(5), 1052-9.

10. Zaman, K., 2010. Tuberculosis: A Global Health Problem, Journal of Health Population and Nutrition. April; 28(2), 111-113.

11. www.who.int/tb/careproviders/ppm/corporate_sector_engage ment_2012.pdf [accessed on July 24, 2013]. 
